PAPER

\title{
Influence of visual stimulus on the precedence effect in sound localization
}

\author{
Toshio Harima ${ }^{1}$, Koji $\mathrm{Abe}^{2}$, Shouichi Takane ${ }^{2}$, Sojun Sato ${ }^{2}$ and Toshio Sone ${ }^{3}$ \\ ${ }^{1}$ Department of Information and Communication Engineering, \\ Tohoku Institute of Technology, \\ 35-1, Yagiyama Kasumi-cho, Taihaku-ku, Sendai, 982-8577 Japan \\ ${ }^{2}$ Department of Electronics and Information Systems, \\ Faculty of Systems Science and Technology, Akita Prefectural University, \\ 84-4 Ebinokuchi, Tsuchiya, Yuri-Honjo, 015-0055 Japan \\ ${ }^{3}$ Emeritus Professor, Tohoku University, \\ 4-9-5 Midorigaoka, Taihaku-ku, Sendai, 982-0021 Japan
}

(Received 30 June 2008, Accepted for publication 26 November 2008)

\begin{abstract}
In this paper we examine how the precedence effect is affected by concurrent visual information about the source of sound. In the experiment, speech, snare drum and guitar sounds were used as sound stimuli, and moving images of the speech utterances or musical performances recorded synchronously with the sounds were presented as visual stimuli. Thus, differences in the lower limit (summing localization threshold, SLT) and the upper limit (echo threshold, ET) of the area where the precedence effect operates were observed when visual stimuli were presented and not presented. As a result, the following conclusions were drawn: 1) The influence of a visual stimulus on SLT was significant for speech and the drum sound, and there was a tendency that SLT was shortened, but for the guitar sound the influence was less significant. 2) The presentation of a visual stimulus along with an auditory stimulus significantly prolonged ET for the guitar sound, but no definite tendency was observed for speech and the drum sound. 3) SLT appears to be significantly influenced by the characteristics of the audiovisual stimulus, particularly by the dynamics of its movement. ET also changed significantly in the presence of a visual stimulus but the change was not uniform; it appeared to depend on the object of attention, i.e., the auditory stimulus, visual stimulus or both.
\end{abstract}

Keywords: Precedence effect, Summing localization, Echo threshold, Sound localization, Audiovisual stimulus

PACS number: 43.66.Qp, 43.66.Lj [doi:10.1250/ast.30.240]

\section{INTRODUCTION}

The basic cues known to be used in sound localization include the time difference and the level difference between signals arriving at both ears. These depend on the direction of the sound source and its distance from the listener [1]. In the case of a sound source located on the median plane, however, no such difference is produced and the interaural difference in the frequency spectrum is the cue used in sound localization [2]. Although such a difference is directly related to the physical properties of the signal, there is also a perceptual phenomenon called the precedence effect, which is relevant to sound localization. This effect implies that a sound is perceived as originating from the direction of the leading sound when two sounds with the same or similar content arrive from different directions within a short time [3,4]. Typically, in a closed space such as a hall or an auditorium with various amounts of reflection and reverberation, it is considered that physical and psychological factors are involved in signal processing performed by the biological system for recognizing the direction of a sound source [5]. Actually, in our daily life, visual as well as auditory information usually helps us perceive the direction of a sound source. When the origin of a sound is not visible, we may try to identify it by turning our head. In such circumstances, sound localization is clearly influenced by visual information. Although in the precedence effect there is some disagreement between the physical characteristic of an auditory stimulus and its sensory perception, it is basically a phenomenon caused by an auditory stimulus. It can be readily presumed, however, that the appearance of the precedence effect might be influenced by a visual stimulus relevant to an auditory one [6]. Various studies have been carried out to obtain data on 
different aspects of the influence of visual information on sound localization. For example, it is known that for visual and auditory signals originating from the same location, a person's attention is naturally drawn to the visual signal rather than to the auditory one $[7,8]$. This is considered to be attributable to both cognitive and sensory factors. In the case of speech, the cognitive factor is caused by the movement of the speaker's mouth and the sensory factor arises from the synchronism of auditory and visual stimuli. A typical example of the former is ventriloquism [9], which relies on an effect similar to the precedence effect. Even if the sound originates from a single source, sound localization is influenced by the visibility of the source $[10,11]$. The results of research into the influence of visual information on sound localization relating to the precedence effect will have important implications in sound field control and/or the use of public address systems in an enclosed space [12]. If the same signal is radiated simultaneously from two loudspeakers located at the same distance from a listener but at an acute angle with each other, the sound is generally localized at the center of the loudspeakers. This condition is called the state of summing localization (SL) and the minimum time difference between the preceding sound and the delayed one above which the precedence effect appears is represented here by the summing localization threshold (SLT). It was reported by Haas and Wallach et al. and some other researchers that SLT is about $1 \mathrm{~ms}[13,14]$. If the time difference between the preceding and the subsequent sound increases, the latter becomes perceptible as an echo. The minimum time delay above which the delayed sound is perceived as an echo is called the echo threshold (ET) [15]. ET is reported to vary from approximately 5 to $30 \mathrm{~ms}$ depending on the type of sound source [16]. Morimoto et al. [17] carried out a study on the influence of a moving picture of the sound source on the precedence effect. They examined the ET when a video was presented on a video monitor placed in front of the subject as well as a sound stimulus (direct sound) followed by its single reflection (echo) of the same intensity after various time lags. A female voice and two different recordings were used as stimulus sounds. The direct sound was emitted through a loudspeaker placed in front of the subject and the delayed sound was emitted from either the front or the left side of the subject. As a result, when a delayed sound originated from the left side, it was found that the echo threshold in the presence of visual information was about $5 \mathrm{~ms}$ longer than those obtained in its absence in most cases, but ET was not easy to determine. They reported that a significant difference was seen in ET between two conditions, with and without pictures, but no definite tendency was observed. In this study, the influence of visual information on ET as well as on SLT was experimentally examined. Not only ET but also SLT must be measured in order to correctly control a sound field and/ or a public address system in an enclosed space, taking into account the influence of visual information on sound localization. Two experiments were executed in this study. Experiment I is concerned with SLT. In this experiment the interaction between hearing and vision was investigated when the time difference between the direct and reflective sounds was as short as $0.1-3.0 \mathrm{~ms}$. Few papers have been reported on this subject. Experiment II is on ET. Although it is similar to the experiment of Morimoto et al., the loudspeaker arrangement for the delayed sound is different. In both experiments, speech, snare drum and guitar sounds were used as sound stimuli, and moving pictures of the speech utterances or the musical performances recorded synchronously with the sounds were presented as visual stimuli. The subjects were asked to indicate the perceived direction of the sound to determine the relation between sound localization and the time delay of the ensuing sounds.

\section{EXPERIMENT I: SLT}

In the experiment designed to determine SLT, the sound image and visual image were placed in the same coordinate system so that they could move independently. The center of the sitting subject was taken as the origin of the coordinates. Twelve different time delays of 0.1 to $3 \mathrm{~ms}$ between the preceding and the following sounds were used as shown in Table 1. The subject was asked to indicate the direction from which the sound originated by pointing with a laser pointer and the data was recorded in a computer.

\subsection{Experimental System for SLT}

The listening test was conducted in a semi anechoic room ( $7.5 \mathrm{~m}$ long, $6.0 \mathrm{~m}$ wide and $4.6 \mathrm{~m}$ high) with the floor covered by sound-absorbing mats. The subject sat on a chair with his/her head fixed loosely to a headrest. Figure 1 shows the loudspeaker arrangement. The main speaker $\left(\mathrm{M}_{\mathrm{Spo}}\right)$ was in front of the subject, while six sub speakers $\left(\mathrm{S}_{\mathrm{Sp} 1}, \mathrm{~S}_{\mathrm{Sp} 2}, \ldots, \mathrm{S}_{\mathrm{Sp} 6}\right)$ were arranged at intervals of $30^{\circ}$ around the subject, $1.3 \mathrm{~m}$ above the floor and on the circumference of a circle of $3 \mathrm{~m}$ radius. The reference sound corresponding to the direct sound was always emitted from the main speaker and the delayed sound

Table 1 Delay times used in the SLT experiment. The stimulus with a random delay time of one of 12 values was presented to the subject, and the perceived direction of the sound image was indicated by the subject with a laser pointer.

12 delay times used in experiment I (ms).

\begin{tabular}{llllll}
\hline 0.1 & 0.2 & 0.3 & 0.4 & 0.5 & 0.6 \\
0.7 & 0.8 & 0.9 & 1.0 & 2.0 & 3.0 \\
\hline
\end{tabular}




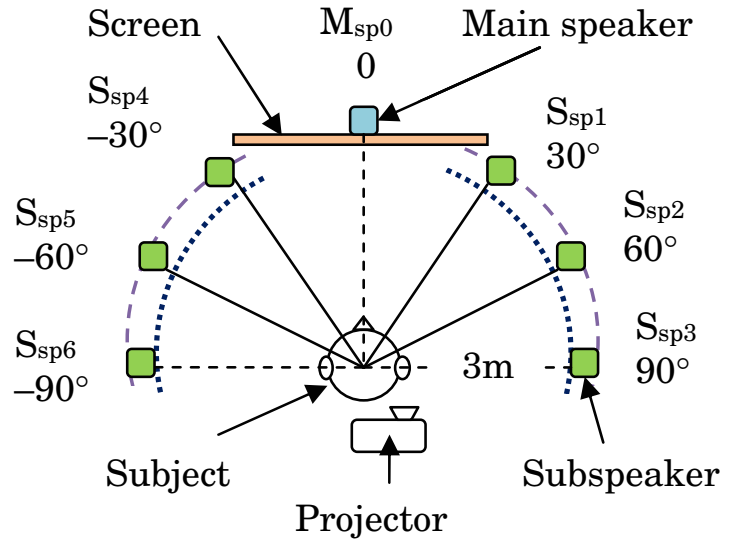

Fig. 1 Positions of the subject and loudspeakers in Experiment I.

was emitted from one of the six subspeakers. A thin curtain was hung in front of the loudspeakers so that their locations were not visible to the subject. In the experiment with moving pictures, the pictures were projected onto a screen $(2.6 \mathrm{~m} \times 2.5 \mathrm{~m})$ installed immediately in front of the main speaker synchronously with the sound stimulus using an Epson ELP-810 projector. If the perceived direction of the sound was confirmed, the subject pushed a button to indicate the direction with a laser pointer, which was recorded in a computer. The preceding sound was always emitted from $\mathrm{M}_{\mathrm{Sp} 0}$, taking the actual conditions in the hall or auditorium into consideration, and the delayed sound was emitted from one of $\mathrm{S}_{\mathrm{Sp} 1}, \mathrm{~S}_{\mathrm{Sp} 2}, \ldots, \mathrm{S}_{\mathrm{Sp} 6}$. The time difference between the preceding and the subsequent sounds was set in advance (Table 1), and transferred to the memory of the Tucker Davis Technology (TDT) System. After the sound pressure was adjusted using the resistance attenuator of the TDT system, the formed signals were presented as the leading sound from the main speaker and as the delayed sound from one of the sub speakers through a channel selector (Fig. 2).

\section{Experimental system}

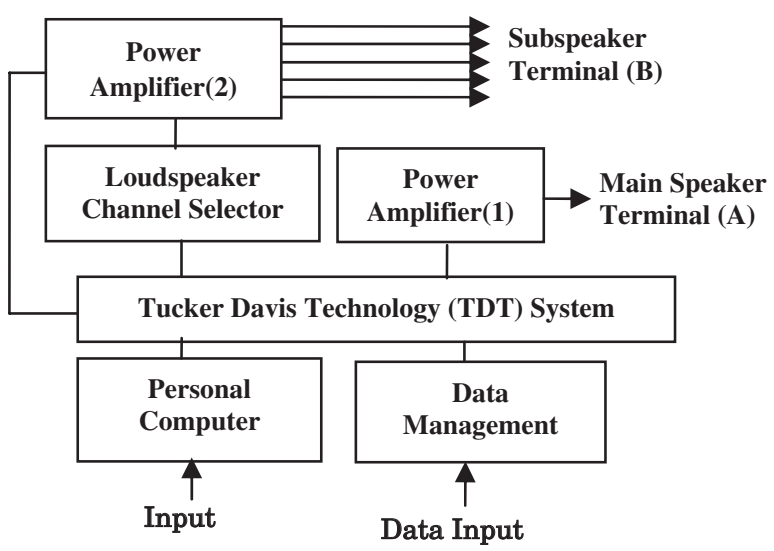

Fig. 2 Arrangement of experimental devices.

\subsection{Sound Stimuli Used in Experiment $I$}

Four different sounds were used as auditory stimuli in experiment I: male and female voices, a snare drum sound and a guitar sound. Speech was adopted because it is the most popular auditory stimulus and also because we were interested in whether a ventriloquism-like effect occurs when the moving picture of the sound source is presented synchronously with the sound. The snare drum sound is impulsive and it was considered to be appropriate for determining the role of dynamic property of sound in the sound localization and precedence effects. In contrast, the guitar sound used in the experiment had a relatively steady characteristic. The visual stimuli were moving pictures recorded when the above sounds were generated. The speaker sat on a chair, the drum player stood and the guitar player sat during the recording of the stimuli. The auditory and visual stimuli were recorded on a digital video camera (Sony DCR-VX9000) in a semianechoic room. The speaker read a weather report in Japanese with the following meaning: "This is the weather report for tomorrow. There will be a cold front and a depression near the Sea of Japan, and wintry conditions will return." The voice stimulus lasted about $7 \mathrm{~s}$. The drum and guitar stimuli were both about $5 \mathrm{~s}$. The sound pressure for $L_{\mathrm{Aeq}}$ was $60 \mathrm{~dB}$ at the center of the subject's head for both the leading and delayed sounds. The visual and auditory stimuli were synchronized using the audiovisual editing software, and the delayed versions of the auditory stimuli were made as sound files, whose output was controlled using the PC. This implies that the accuracy of synchronization between the visual and auditory stimuli was less than the sampling accuracy of the auditory stimulus itself, which was set to approximately $1 / 48000 \mathrm{~s}$.

\subsection{Response in SLT Measurement}

After explaining the aim and the procedure of the experiment, each subject had ten practice trials as training prior to the data acquisition. The subjects were five university students: three males and two females with normal hearing and normal/corrected normal vision. They were asked to listen to the sound presented and to indicate its perceived direction. For speech, the stimulus presentation $(7 \mathrm{~s})$ was followed by a $3 \mathrm{~s}$ interval for response. For the drum and guitar, the $5 \mathrm{~s}$ sound stimulus was followed by $3 \mathrm{~s}$ response time. The subject responded by turning the laser pointer toward the perceived direction of the sound and pushing a button to confirm his/her decision. If the direction to be indicated was too broad, the subject was asked to point to the center of the range. When the subject could not identify the perceived direction with a single move, the stimulus could be presented again. There were twelve delay times in the experiment, the number of times each sound was repeated was five, the number of directions 
(a): Without visual stimulus

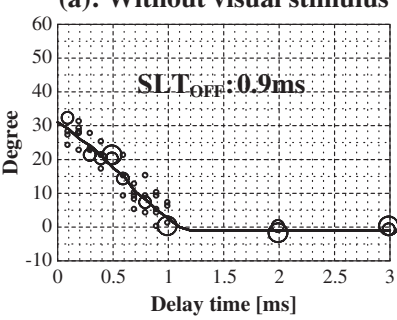

(b): With visual stimulus

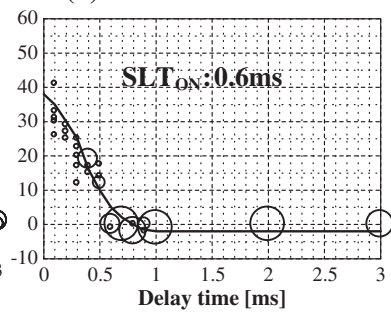

Fig. 3 Relationship between the delay time of the second sound and perceived direction of sound. Subject: ST. Subspeaker angle: $60^{\circ}$. Source: speech (male voice). (a): Without visual stimulus

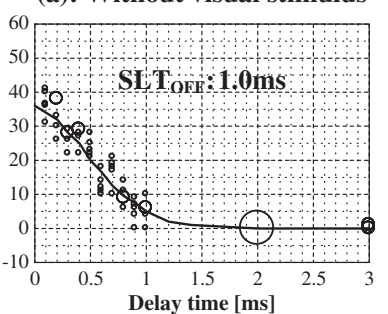

(b): With visual stimulus

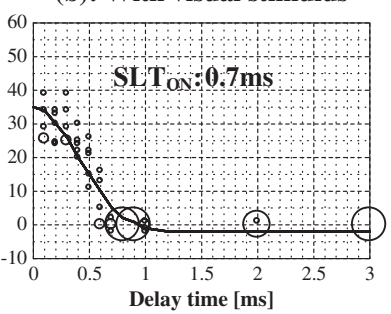

Fig. 4 Relationship between the delay time of the second sound and perceived direction of sound. Subject: ST. Subspeaker angle: $60^{\circ}$. Source: speech (female voice).

of the delayed sound was six, the number of different source sounds was four and the experiment was performed with and without a visual stimulus. Thus, the total number of trials was 2,880 for each subject.

\subsection{Results and Discussion of Experiment I}

The results for subject ST are shown in Figs. 3 to 6 . Circles in the figures represent the perceived direction of the stimulus sound and their size corresponds to the frequency of response. According to this figure, the perceived direction of the sound is located near the midpoint of $\mathrm{M}_{\mathrm{Spo}}$ and $\mathrm{S}_{\mathrm{Sp} 2}$ when two sounds arrive simultaneously. This is in the area of SL. If the time difference between the preceding sound and the delayed one increases, the sound is localized toward the preceding sound. The fitting curves in Figs. 3 to 6 were normal distribution curves that must closely fitted the data with the mean value for each delay time, which was calculated by averaging the data in the range from the first quartile to the third quartile to avoid the contribution of extreme judgments. SLT was defined as the delay time at which the localized direction of a sound came within the range of the front $\pm 5^{\circ}$ on the curve. The magnitude of the effect of the visual stimulus is defined as the difference between SLTs with and without the visual stimulus, that is, SLT OFF $_{\text {}}$ (without visual stimulus) $-\mathrm{SLT}_{\mathrm{ON}}$ (with visual stimu-
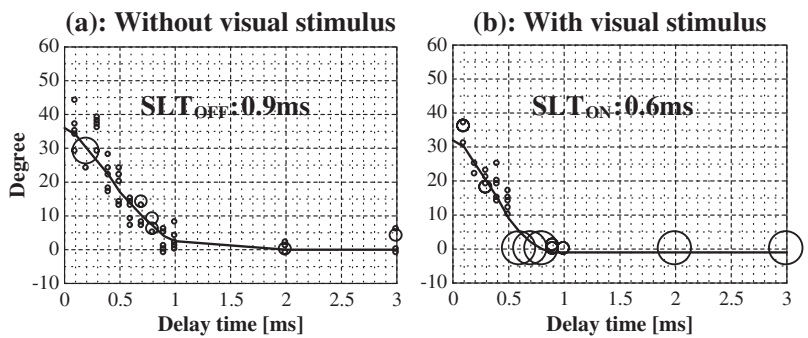

Fig. 5 Relationship between the delay time of the second sound and perceived direction of sound. Subject: ST. Subspeaker angle: $60^{\circ}$. Source: snare drum.

(a): Without visual stimulus

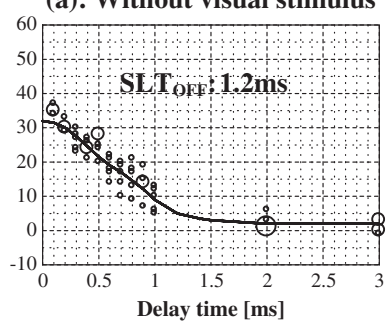

(b): With visual stimulus

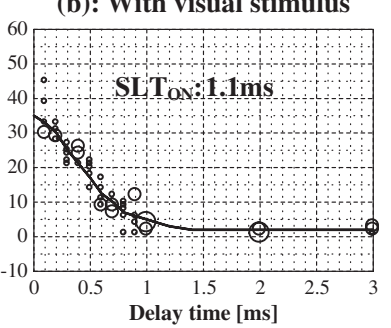

Fig. 6 Relationship between the delay time of the second sound and perceived direction of sound. Subject: ST. Subspeaker angle: $60^{\circ}$. Source: guitar.

lus) $=\mathrm{VE}$ (effect of visual stimulus). SLT and VE are shown in Table 2 for the sub speakers with different directions. In this table the effect of the visual stimulus is found to be about $0.39 \mathrm{~ms}$ for speech (both male and female voices). For the snare drum, the effect is similar to speech, but for the guitar the effect is smaller as about $0.13 \mathrm{~ms}$. As a result of applying the $t$-test to the mean values of the curves corresponding to results for without and with a visual stimulus, the effect of the presentation of the visual stimulus is statistically significant at the 0.01 level under the condition that the subspeaker is within $\pm 60^{\circ}$ of the main speaker (Table 3). For a subspeaker located at $\pm 90^{\circ}$ to the main speakers, significant change due to the presentation of the visual stimulus was observed. In Table 4 , the percentages by which SLT moved to a longer time difference or a shorter time difference by adding a visual stimulus are shown for the five subjects. In more than $60 \%$ of the data, there is a tendency that the precedence effect occurs at a shorter time difference by adding visual information. In most subjects the transition from SL to localization by the precedence effect occurs at a shorter time difference for speech and the snare drum. Also in the case of the guitar, when the delayed sound originates from within $\pm 60^{\circ}$ of $\mathrm{M}_{\text {Spo }}$, the transition of sound localization from SL to that due to the precedence effect occurs at a shorter time difference with the visual stimulus than without the visual stimulus, although it is not as 
Table 2 Influence of the visual stimulus classified by stimulus sound. Subject: ST. Without visual stimulus: OFF [ms]. With visual stimulus: ON [ms]. Visual effect average: $\mathrm{VE}(\mathrm{OFF}-\mathrm{ON})$. Sound pressure: $60 \mathrm{~dB}(\mathrm{~A})$ (at the center of the subject's head).

\begin{tabular}{|c|c|c|c|c|c|c|c|c|c|c|c|c|c|}
\hline \multirow{2}{*}{$\begin{array}{l}\text { Direction of SP } \\
\text { Visual stimulus }\end{array}$} & \multicolumn{2}{|c|}{$30^{\circ}$} & \multicolumn{2}{|c|}{$60^{\circ}$} & \multicolumn{2}{|c|}{$90^{\circ}$} & \multicolumn{2}{|c|}{$-30^{\circ}$} & \multicolumn{2}{|c|}{$-60^{\circ}$} & \multicolumn{2}{|c|}{$-90^{\circ}$} & \multirow[b]{2}{*}{ VE } \\
\hline & OFF & ON & OFF & ON & OFF & $\mathrm{ON}$ & OFF & $\mathrm{ON}$ & OFF & ON & OFF & $\mathrm{ON}$ & \\
\hline $\begin{array}{c}\text { Speech } \\
\text { (male voice) }\end{array}$ & 0.6 & 0.3 & 0.9 & 0.6 & 1.1 & 0.6 & 0.4 & 0.0 & 0.7 & 0.3 & 0.9 & 0.5 & 0.38 \\
\hline $\begin{array}{c}\text { Speech } \\
\text { (female voice) }\end{array}$ & 0.7 & 0.5 & 1.0 & 0.7 & 1.1 & 0.8 & 0.6 & 0.2 & 0.9 & 0.4 & 1.0 & 0.5 & 0.40 \\
\hline Snare drum & 0.7 & 0.3 & 0.9 & 0.6 & 1.0 & 0.6 & 0.3 & 0.0 & 0.6 & 0.3 & 0.9 & 0.4 & 0.37 \\
\hline Guitar & 1.0 & 0.9 & 1.2 & 1.1 & 1.4 & 1.3 & 0.3 & 0.2 & 0.7 & 0.5 & 0.8 & 0.7 & 0.13 \\
\hline
\end{tabular}

Table 3 Results of $t$-test for the significant difference (SD) between mean values without and with visual stimulus. Subject: ST. $\bigcirc$ : Statistically significant at 0.01 level $(p<0.01) . \times$ : No significant difference is seen. With visual stimulus: ON $[\mathrm{ms}]$. The numerals in parentheses show the standard deviations.

\begin{tabular}{|c|c|c|c|c|c|c|c|c|c|c|c|c|}
\hline \multirow{2}{*}{$\begin{array}{l}\text { Direction of } \\
\text { subspeaker }\end{array}$} & \multicolumn{3}{|c|}{ Speech (male voice) } & \multicolumn{3}{|c|}{ Speech (female voice) } & \multicolumn{3}{|c|}{ Snare drum } & \multicolumn{3}{|c|}{ Guitar } \\
\hline & SD & OFF & $\mathrm{ON}$ & SD & OFF & $\mathrm{ON}$ & SD & OFF & $\mathrm{ON}$ & SD & OFF & $\mathrm{ON}$ \\
\hline \multirow{2}{*}{$90^{\circ}$} & $x$ & 0.30 & 0.27 & $x$ & 0.50 & 0.40 & $x$ & 0.40 & 0.40 & $x$ & 0.50 & 0.40 \\
\hline & $t(59)=0.39$ & $(0.50)$ & $(0.28)$ & $t(59)=1.7$ & $(0.40)$ & $(0.20)$ & $t(59)=0.0$ & $(0.40)$ & $(0.24)$ & $t(59)=1.3$ & $(0.34)$ & $(0.49)$ \\
\hline \multirow{2}{*}{$60^{\circ}$} & 0 & 0.60 & 0.30 & 0 & 0.60 & 0.40 & 0 & 0.50 & 0.20 & $x$ & 0.60 & 0.50 \\
\hline & $t(59)=5.1$ & $(0.37)$ & $(0.26)$ & $t(59)=3.14$ & $(0.40)$ & $(0.28)$ & $t(59)=5.0$ & $(0.40)$ & $(0.22)$ & $t(59)=0.9$ & $(0.78)$ & $(0.40)$ \\
\hline \multirow{2}{*}{$30^{\circ}$} & 0 & 0.50 & 0.20 & 0 & 0.50 & 0.30 & 0 & 0.50 & 0.30 & $x$ & 0.60 & 0.50 \\
\hline & $t(59)=4.5$ & $(0.50)$ & $(0.10)$ & $t(59)=3.4$ & $(0.40)$ & $(0.20)$ & $t(59)=3.7$ & $(0.40)$ & (0.10) & $t(59)=1.1$ & $(0.50)$ & $(0.50)$ \\
\hline \multirow{2}{*}{$-30^{\circ}$} & 0 & 0.40 & 0.20 & 0 & 0.40 & 0.20 & 0 & 0.30 & 0.10 & 0 & 0.40 & 0.10 \\
\hline & $t(59)=$ & $(0.50)$ & $(0.20)$ & $t(59)=2.8$ & $(0.50)$ & $(0.22)$ & $t(59)=3.0$ & $(0.48)$ & $(0.14)$ & $t(59)=3.3$ & $(0.50)$ & (0.48) \\
\hline \multirow{2}{*}{$-60^{\circ}$} & 0 & 0.40 & 0.20 & 0 & 0.50 & 0.20 & 0 & 0.40 & 0.20 & $x$ & 0.60 & 0.50 \\
\hline & $t(59)=7.3$ & $(0.32)$ & $(0.10)$ & $t(59)=3.8$ & $(0.37)$ & $(0.14)$ & $t(59)=3.7$ & $(0.40)$ & $(0.10)$ & $t(59)=1.5$ & $(0.40)$ & (0.30) \\
\hline \multirow{2}{*}{$-90^{\circ}$} & $x$ & 0.37 & 0.30 & $x$ & 0.50 & 0.40 & $x$ & 0.40 & 0.30 & $x$ & 0.40 & 0.30 \\
\hline & ) $=$ & $(0.40)$ & $(0.17)$ & ) $=$ & $(0.44)$ & $(0.20)$ & $t(59)=1.7$ & $(0.40)$ & $(0.17)$ & $t(59)=1.3$ & $(0.40)$ & (0.40) \\
\hline
\end{tabular}

noticeable as with speech or the snare drum. One of the five subjects was not influenced by the presence of a visual stimulus. A possible reason for this is that hearing and vision may increase or decrease in sensitivity depending on the degree of active attention (intentional) or passive attention incidental to the stimulus concerned. Research of Maruyama and Sasaki [18] shows an intersensory effect between vision and hearing. They explain that there is an effect of promotion or restraint due to the concentration of the attention on visual or auditory sensations depending on the focus of the subject. This argument may apply in our case. Namely, the subject is thought to have concentrated his attention on the sound stimulus rather than the visual one; thus, he was little influenced by the visual stimulus during sound localization. It was shown by Haas and Wallach et al., that $\mathrm{SLT}_{\mathrm{OFF}}$ is about $1 \mathrm{~ms}$ unless a visual stimulus is given. In our experiment, the average SLT $_{\mathrm{OFF}}$ of the subject (ST) is about $0.8 \mathrm{~ms}$ for the speech and snare drum and about $0.9 \mathrm{~ms}$ for the guitar (Table 2). There is a reasonably good correspondence between the previous researchers' results and ours, although our results suggest a slightly shorter time difference. Regarding the influence of a visual stimulus on sound localization, vision appears to have a strange effect that hearing, i.e., the sound image is drawn toward the visual stimulus. This phenomenon has been known in ventriloquism for many years. In our experiment there was a marked influence of the visual stimuli on the precedence effect for speech (both male and female voices) for subspeakers located at $\pm 30^{\circ}$ and $\pm 60^{\circ}$, and VE for the SLT was about $0.39 \mathrm{~ms}$. The influence of the visual stimulus was particularly noticeable for the speech and snare drum. This fact is thought to originate from the dynamics of the movement at the sound source, i.e., the brisk movement of lips and the movement of the speaker's head when speaking and the action of beating the drum with sticks. It is presumed that in these cases the active movement of the source influenced the subjects' perception, whereas for guitar playing, the movement of the player during the performance was more limited.

\section{EXPERIMENT II: ET}

In experiment II we examined the influence of a visual stimulus on ET, i.e., the minimum time difference between a preceding sound and a delayed one at which an echo is perceived. To determine this threshold, two methods have been used in the past. One is the method of obtaining the 
Table 4 Influence of visual stimulus on SLT. Subjects: Five persons (O, S, ST, SY and W). (1): Percentage of responses in which SLT is shortened by addition of visual stimulus (\%). (2): Percentage of responses in which SLT is prolonged by addition of visual stimulus (\%). The percentages show the rate at which SLT is shortened by $60 \%$ or more by adding a visual stimulus for the five subjects. The numerals include only the responses that showed a statistical difference between the results with and without a visual stimulus.

\begin{tabular}{|c|c|c|c|c|c|c|c|c|}
\hline \multirow{2}{*}{$\begin{array}{l}\text { Direction of } \\
\text { subspeaker }\end{array}$} & \multicolumn{2}{|c|}{ Speech (male voice) } & \multicolumn{2}{|c|}{ Speech (female voice) } & \multicolumn{2}{|c|}{ Snare drum } & \multicolumn{2}{|c|}{ Guitar } \\
\hline & (1) & (2) & (1) & (2) & (1) & (2) & (1) & (2) \\
\hline $90^{\circ}$ & 60 & 20 & 40 & 20 & 60 & 40 & 40 & 20 \\
\hline $60^{\circ}$ & 80 & 20 & 60 & 0 & 80 & 0 & 80 & 0 \\
\hline $30^{\circ}$ & 80 & 20 & 80 & 20 & 100 & 0 & 80 & 0 \\
\hline$-30^{\circ}$ & 100 & 0 & 80 & 20 & 100 & 0 & 80 & 0 \\
\hline$-60^{\circ}$ & 80 & 20 & 100 & 0 & 80 & 20 & 40 & 40 \\
\hline$-90^{\circ}$ & 60 & 40 & 40 & 20 & 60 & 40 & 40 & 40 \\
\hline
\end{tabular}

absolute threshold defined by Burgtorf [15] and Seraphim [16] (Wahrnehmbarkeitsschwelle, abbreviated to aWs). In this method ET is represented by the minimum time difference at which any discrepancy such as the deviation in timbre from the standard stimulus is pesceived, even though a clear echo is not heard. Another criterion is that adopted by Tahara et al. [19], who used two alternative forced-choice tasks. In their experiment, a subject was asked to answer whether the preceding sound and the delayed one were fused together or were separate. In our experiment, the second criterion was adopted. It was assumed that ET was less than $30 \mathrm{~ms}$, and therefore the time difference between stimuli was varied between 1 and $30 \mathrm{~ms}$. In the experiment, 30 different delay times, shown in Table 5, were used and the maximum likelihood method was used to obtain ET. As an initial condition, it was assumed that a single sound was perceived for a $1 \mathrm{~ms}$ time difference between the preceding and following sounds and that an echo was heard for a $30 \mathrm{~ms}$ time delay. Using the maximum likelihood estimation it is possible that an estimate converges on an erroneous value if a subject makes a careless mistake in judgment, because the stimulus condition is chosen on the basis of the preceding judgment in the maximum likelihood method. Therefore, the randomized maximum likelihood method was used, where a random value was added to an initial estimate in order to reduce the possibility of convergence to an erroneous

Table 5 Delay times used in experiment II (ET). It was assumed for the experiment that a single sound was heard at $1 \mathrm{~ms}$ time delay and that two sounds were heard at $30 \mathrm{~ms}$ time delay. ET was obtained using the maximum likelihood method.

Delay times used in experiment II: 30 values (ms)

\begin{tabular}{rrrrrrrr}
\hline 1.0 & 2.0 & 3.0 & 4.0 & 5.0 & 6.0 & 7.0 & 8.0 \\
9.0 & 10.0 & 11.0 & 12.0 & 13.0 & 14.0 & 15.0 & 16.0 \\
17.0 & 18.0 & 19.0 & 20.0 & 21.0 & 22.0 & 23.0 & 24.0 \\
25.0 & 26.0 & 27.0 & 28.0 & 29.0 & 30.0 & & \\
\hline
\end{tabular}

result. ET was obtained under the above assumption using the maximum likelihood method [20]. The influence of the visual stimulus on ET was considered on the basis of the results.

\subsection{Experimental Conditions and the Method of Response in Experiment II}

The experiment was performed in a semianechoic room similarly to experiment I. The subjects and audiovisual stimuli were the same as those in experiment I. The experiment was explained to the subjects including the use of the data logger, and subjects were given ten trials prior to the actual experiment. They were asked to say whether they heard a single sound or two successive sounds. When a single sound was perceived, the subject pushed the first button on the data logger, and if two sounds were heard, he/she pushed the second button. In addition, the subjects were asked to indicate the perceived direction of the sound with a laser pointer if a single sound was heard. The number of judgments was 2,400 including six directions of delayed sound, four different sound stimuli, the presentation of a visual stimulus or not and fifty trials under the same conditions.

\subsection{Results and Considerations of Experiment II}

Examples of the results from subject $\mathrm{O}$ are shown in Figs. 7 to 10. In the figures, the abscissa shows the time delay of the second sound from the preceding one and the ordinate denotes the proportion of trials in which two sounds were heard. If a subject heard only a single sound, the ordinate ought to show a zero value. The time difference at which the rate of response that two sounds were heard reached $75 \%$ was defined as ET. The broken line in the figures represents the results when no visual stimulus was presented, and the solid line shows the results when a visual stimulus was presented. Cumulative normal distribution curves were fitted to the points obtained experimentally. From Fig. 7(a), $\mathrm{ET}_{\mathrm{OFF}}$ for the male speaker 

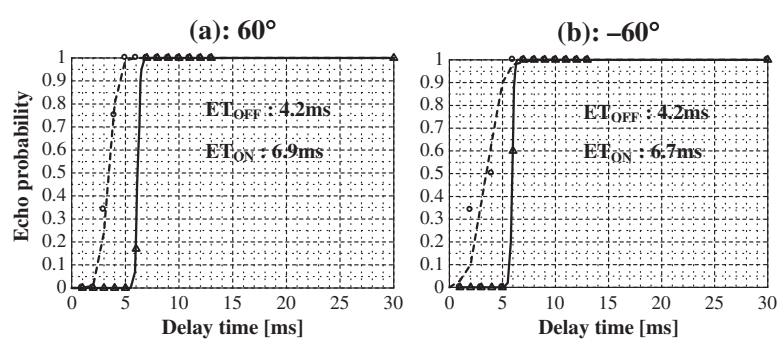

Fig. 7 Relationship between time delay of the second sound and echo probability. ---: Without visual stimulus. - : With visual stimulus. Subject: O. Source: Speech (male voice).
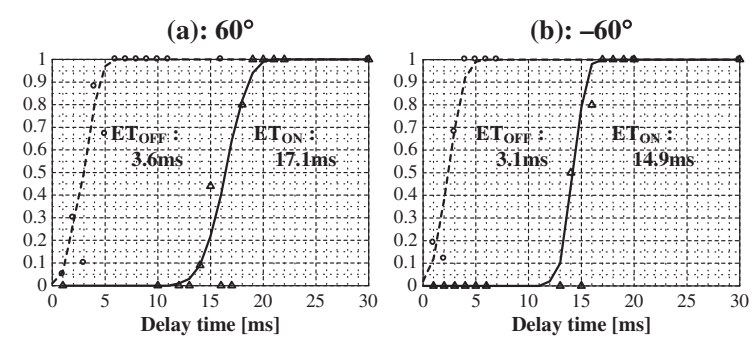

Fig. 8 Relationship between the time delay of the second sound and echo probability. ---: Without visual stimulus. - : With visual stimulus. Subject: O. Source: speech (female voice).

obtained by subject $\mathrm{O}$ for a subspeaker at $60^{\circ}$ with no visual stimulus is about $4.2 \mathrm{~ms}$, and $\mathrm{ET}_{\mathrm{ON}}$ with the accompaniment of a visual stimulus is about $6.9 \mathrm{~ms}$. The difference between those values, $2.7 \mathrm{~ms}$, shows the degree of influence of the visual information on the echo threshold. The difference between $\mathrm{ET}_{\mathrm{OFF}}$ and $\mathrm{ET}_{\mathrm{ON}}$ for the female speaker (Fig. 8(a)), on the other hand, is about $13.5 \mathrm{~ms}$, i.e., the influence of the visual image is noticeably greater than that of the male voice. For the snare drum (Fig. 9(a)), the influence of the visual stimulus was about $2.3 \mathrm{~ms}$ while that for the guitar (Fig. 10(a)), was about $0.3 \mathrm{~ms}$. Although the influence of the visual stimulus is dependent on the type of sound for subject O, ET tends to be prolonged in the presence of visual information except for the guitar sound. For subject ST, on the other hand, the influence of the visual stimulus on $\mathrm{ET}\left(\mathrm{ET}_{\mathrm{ON}}-\mathrm{ET}_{\mathrm{OFF}}\right)$ for a subspeaker at $60^{\circ}$ is $-2.0 \mathrm{~ms}$ for male speech and the drum, in the opposite direction compared with that for subject $\mathrm{O}$. For the guitar sound, however, the influence $\left(\mathrm{ET}_{\mathrm{ON}}-\mathrm{ET}_{\mathrm{OFF}}\right)$ is $8.5 \mathrm{~ms}$, which is far greater than that for subject $\mathrm{O}$. To investigate this difference more precisely, the influence of the visual stimulus on ET was examined by a $t$-test applied to the mean values (see Table 6). The numerical values in the table show the average ET and symbols denote the results of the $t$-test. The result for subject $\mathrm{O}$ shows that there is a statistically significant difference between ET with and without the visual stimulus for speech and the
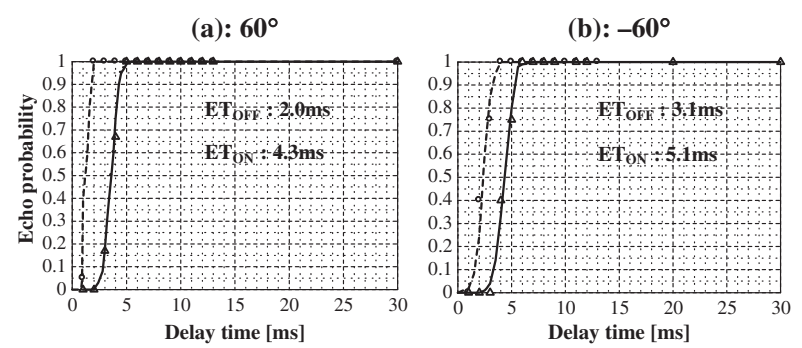

Fig. 9 Relationship between the time delay of the second sound and echo probability. ---: Without visual stimulus. - : With visual stimulus. Subject: O. Source: Snare drum.
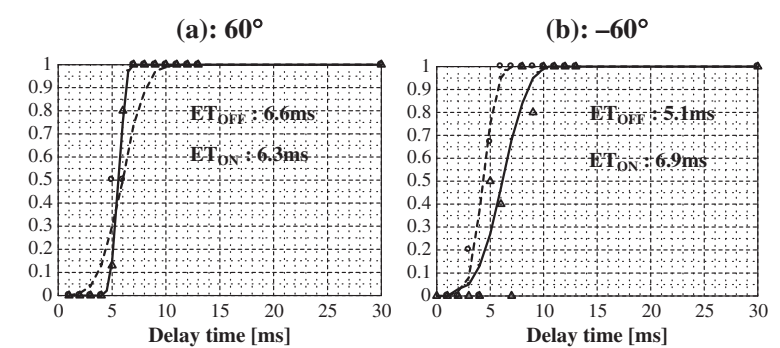

Fig. 10 Relationship between the time delay of the second sound and echo probability. - - -: Without visual stimulus. - With visual stimulus. Subject: O. Source: Guitar.

snare drum at the 0.01 level, and $\mathrm{ET}_{\mathrm{ON}}$ is longer than $\mathrm{ET}_{\mathrm{OFF}}$. The result for subject $\mathrm{ST}$ also shows a significant difference (see Table 7). In this case, however, the influence $\left(\mathrm{ET}_{\mathrm{ON}}-\mathrm{ET}_{\mathrm{OFF}}\right)$ is negative for speech and the snare drum, but $8.5 \mathrm{~ms}$, for the guitar sound, longer than that for subject $\mathrm{O}$. Thus, the sound localization has a different tendency among subjects, even though there is a significant difference between sound presentations with and without a visual stimulus. As seen from Tables 6 and 7 , the influence of visual information on ET is classified into three types: ET is shortened, ET is prolonged and no difference is seen, upon the addition of visual information. Summarizing the results for the five subjects as seen from Table 8, ET is shortened for subjects $\mathrm{S}$ and ST by presenting visual stimuli, and prolonged for subjects $\mathrm{O}$ and SY for the speech and the snare drum. For the guitar sound, ET is about $5 \mathrm{~ms}$ longer in the presence of the visual stimulus than in its absence for four subjects out of five. For subject W, the influence of the visual stimulus is not seen. Thus, even though visual information significantly affects sound localization, its tendency and effectiveness are vary among subjects. Maruyama et al. [18] discussed the mutual effects between vision and audition, and stated that auditory localization and the recognition of sound are achieved through the so-called psychological intermodality and/or consonance, which are common in human susceptibilities to sound and vision. They assumed that the 
Table 6 Results of $t$-test for the significant difference between mean ET values. Subject: O. The time difference at which the rate of response that two sounds were heard reached $75 \%$ was defined as ET. Without visual stimulus: OFF [ms]. With visual stimulus: $\mathrm{ON}[\mathrm{ms}]$. Numerical values show $\mathrm{ET}\left(\mathrm{OFF}=\mathrm{ET}_{\mathrm{OFF}}, \mathrm{ON}=\mathrm{ET}_{\mathrm{ON}}\right)$. $\bigcirc$ : Statistically significant difference between $\mathrm{ET}_{\mathrm{ON}}$ and $\mathrm{ET}_{\mathrm{OFF}}$ at 0.01 level $(p<0.01) . \times$ : No significant difference is seen. SD: Significant difference.

\begin{tabular}{|c|c|c|c|c|c|c|c|c|c|c|c|c|}
\hline \multirow{2}{*}{$\begin{array}{l}\text { Direction of } \\
\text { subspeaker }\end{array}$} & \multicolumn{3}{|c|}{ Speech (male voice) } & \multicolumn{3}{|c|}{ Speech (female voice) } & \multicolumn{3}{|c|}{ Snare drum } & \multicolumn{3}{|c|}{ Guitar } \\
\hline & SD & OFF & $\mathrm{ON}$ & $\mathrm{SD}$ & OFF & $\mathrm{ON}$ & SD & OFF & $\mathrm{ON}$ & $\mathrm{SD}$ & OFF & ON \\
\hline $90^{\circ}$ & $t(49)=7.5$ & 5.3 & 7.8 & $t(49) \stackrel{\bigcirc}{=} 31.4$ & 4.8 & 11.2 & $\begin{array}{c}\bigcirc \\
t(49)=4.4\end{array}$ & 2.6 & 3.5 & $\begin{array}{c}\times \\
t(49)=2.5\end{array}$ & 5.7 & 6.2 \\
\hline $60^{\circ}$ & $\begin{array}{c}\bigcirc \\
t(49)=13.2\end{array}$ & 4.2 & 6.9 & $t(49) \stackrel{\bigcirc}{=} 66.1$ & 3.6 & 17.1 & $t(49) \stackrel{\bigcirc}{=} 11.3$ & 2.0 & 4.3 & $\begin{array}{c}\times \\
t(49)=2.5\end{array}$ & 6.6 & 6.3 \\
\hline $30^{\circ}$ & $\begin{array}{c}\bigcirc \\
t(49)=7.8\end{array}$ & 5.1 & 6.7 & $t(49)=58.3$ & 5.6 & 17.5 & $\begin{array}{c}\times \\
t(49)=1.5\end{array}$ & 2.8 & 3.1 & $\begin{array}{c}\times \\
t(49)=1.5\end{array}$ & 4.1 & 4.8 \\
\hline$-30^{\circ}$ & $t(49) \stackrel{\bigcirc}{=} 12.3$ & 4.7 & 7.2 & $t(49) \stackrel{\bigcirc}{=} 65.2$ & 4.9 & 18.2 & $\begin{array}{c}\bigcirc \\
t(49)=14.7\end{array}$ & 3.1 & 6.1 & $\begin{array}{c}\bigcirc \\
t(49)=8.3\end{array}$ & 4.7 & 6.8 \\
\hline$-60^{\circ}$ & $t(49)=12.2$ & 4.2 & 6.7 & $t(49) \stackrel{\bigcirc}{=} 57.8$ & 3.1 & 14.9 & $t(49)=11.8$ & 3.1 & 5.1 & $t(49)=8.8$ & 5.1 & 6.9 \\
\hline$-90^{\circ}$ & $\begin{array}{c}0 \\
t(49)=5.4\end{array}$ & 5.2 & 6.3 & $\begin{array}{c}\bigcirc \\
t(49) \stackrel{1}{=} 42.1\end{array}$ & 2.8 & 11.4 & $\begin{array}{c}0 \\
t(49)=4.9\end{array}$ & 4.0 & 3.0 & $\begin{array}{c}\times \\
t(49)=2.5\end{array}$ & 8.0 & 7.4 \\
\hline
\end{tabular}

Table 7 Results of $t$-test for the significant difference between mean ET values. Subject: ST. The time difference at which the rate of response that two sounds were heard reached $75 \%$ was defined as ET. Without visual stimulus: OFF [ms]. With visual stimulus: $\mathrm{ON}[\mathrm{ms}]$. Numerical values show $\mathrm{ET}\left(\mathrm{OFF}=\mathrm{ET}_{\mathrm{OFF}}, \mathrm{ON}=\mathrm{ET}_{\mathrm{ON}}\right) . \bigcirc:$ Statistically significant difference between $\mathrm{ET}_{\mathrm{ON}}$ and $\mathrm{ET}_{\mathrm{OFF}}$ at 0.01 level $(p<0.01)$. $\times$ : No significant difference is seen. SD: Significant difference.

\begin{tabular}{|c|c|c|c|c|c|c|c|c|c|c|c|c|}
\hline \multirow{2}{*}{$\begin{array}{l}\text { Direction of } \\
\text { subspeaker }\end{array}$} & \multicolumn{3}{|c|}{ Speech (male voice) } & \multicolumn{3}{|c|}{ Speech (female voice) } & \multicolumn{3}{|c|}{ Snare drum } & \multicolumn{3}{|c|}{ Guitar } \\
\hline & SD & OFF & $\mathrm{ON}$ & SD & OFF & $\mathrm{ON}$ & SD & OFF & $\mathrm{ON}$ & SD & OFF & ON \\
\hline $90^{\circ}$ & $t(49) \stackrel{\bigcirc}{=} 11.3$ & 7.6 & 5.3 & $\begin{array}{c}\bigcirc \\
t(49)=21.1\end{array}$ & 10.1 & 5.8 & $\begin{array}{c}\times \\
t(49)=2.0\end{array}$ & 4.2 & 4.6 & $t(49)=48.9$ & 8.9 & 18.9 \\
\hline $60^{\circ}$ & $t(49)=9.8$ & 7.4 & 5.4 & $t(49) \stackrel{\bigcirc}{=} 12.7$ & 10.1 & 7.5 & $\begin{array}{c}0 \\
t(49)=9.8\end{array}$ & 7.1 & 5.1 & $t(49)=40.2$ & 6.4 & 14.6 \\
\hline $30^{\circ}$ & $\begin{array}{c}O \\
t(49)=7.3\end{array}$ & 7.5 & 6.0 & $t(49)=23.0$ & 10.7 & 6.0 & $t(49) \stackrel{\bigcirc}{=} 13.2$ & 7.1 & 4.4 & $t(49)=29.4$ & 7.5 & 13.4 \\
\hline$-30^{\circ}$ & $t(49)=8.8$ & 7.2 & 5.4 & $t(49)=17.6$ & 10.0 & 6.4 & $\begin{array}{c}\times \\
t(49)=1.5\end{array}$ & 4.4 & 4.7 & $t(49)=7.4$ & 7.9 & 9.4 \\
\hline$-60^{\circ}$ & $\begin{array}{c}\times \\
t(49) \stackrel{0}{=} 0.98\end{array}$ & 5.9 & 5.7 & $\begin{array}{c}\bigcirc \\
t(49)=15.2\end{array}$ & 9.5 & 6.4 & $t(49)=6.9$ & 4.1 & 5.5 & $t(49) \stackrel{\bigcirc}{=} 20.1$ & 13.2 & 9.1 \\
\hline$-90^{\circ}$ & $\begin{array}{c}\times \\
t(49)=0.0\end{array}$ & 4.8 & 4.8 & $\begin{array}{c}\bigcirc \\
t(49)=25.0\end{array}$ & 10.1 & 5.0 & $\begin{array}{c}\bigcirc \\
t(49)=5.9\end{array}$ & 4.9 & 3.7 & $t(49) \stackrel{\bigcirc}{=} 40.2$ & 19.7 & 11.5 \\
\hline
\end{tabular}

Table 8 Influence of the visual stimulus on ET for each subject. Five subjects: S, ST, O, SY, and W. Influences are classified into three types: (1) ET is shortened, (2) ET is prolonged and (3) no difference is seen upon the addition of visual information.

\begin{tabular}{cccc}
\hline Category of stimulus sound & (1) ET is shortened & (2) ET is prolonged & (3) No difference is seen \\
\hline $\begin{array}{c}\text { Speech (male, female voice) } \\
\text { and snare drum } \\
\text { Guitar }\end{array}$ & S, ST & O, SY & W \\
\hline
\end{tabular}

localization of an object is affected by which sense is more attracted by the stimulus, hearing or vision. From this point of view, the difference in the influence of vision on sound localization among the subjects is interpreted as being caused by how much the subject paid attention to the visual stimulus. Morimoto et al. [17] also reported on the basis of a $t$-test that the influence of visual stimuli on ET is statistically significant at the 0.05 level, but ET may sometimes be prolonged and sometimes be shortened, and that there is no definite tendency. Our results show almost the same tendency for speech and the snare drum as those obtained by Morimoto et al. For guitar playing, however, ET is significantly prolonged in every subject by the addition of a visual stimulus. This fact suggests that the influence of visual information on the precedence effect depends upon the type of sound stimulus, and on how much attention is directed by a subject to the auditory stimulus as opposed to the visual stimulus. 


\section{CONCLUSION}

In this study the influence of visual stimuli on the precedence effect was considered through experiments under various conditions. Changes in the lower limit (SLT) and the upper limit (ET) of the area in which the precedence effect operates were observed when visual stimuli were presented. As a result, the following conclusions were obtained:

1) The influence of a visual stimulus on SLT was significant for speech and the drum sound, and there was a tendency that SLT was shortened (about $0.34 \mathrm{~ms}$ ), but for the guitar sound the influence was smaller (about $0.13 \mathrm{~ms}$ ).

2) The presentation of a visual stimulus along with an auditory stimulus significantly prolonged ET (by about $5 \mathrm{~ms}$ ) for the guitar sound, but no definite tendency was observed for speech and the drum sound.

3) SLT appears to be significantly influenced by the characteristics of the audiovisual stimulus and the dynamics of the source movement. ET also changed significantly in the presence of a visual stimulus but the change was not uniform. ET appears to depend on the object of attention, i.e., the auditory stimulus, the visual stimulus or both. In summary, it appears that the spatial and temporal accordance of an auditory sensation with a visual sensation and the psychological attention of a subject are important factors in actual sound localization. Even though the influence of visual stimuli on the precedence effect is significant, there is some variance among subjects and further investigation is needed. In experiment I (SLT) and experiment II (ET) performed in this study, it was clarified that the influence of a visual stimulus on an auditory stimulus is statistically significant in terms of the precedence effect. The observations discussed in this paper are indispensable factors for considering the sound field in a room and public address systems to be used in it.

\section{ACKNOWLEDGMENTS}

The authors express their gratitude to professor $\mathrm{T}$. Takano, Tohoku Institute of Technology, for his support. The authors also wish to thank Messrs. S. Ito and D. Sunada, graduates of Akita Prefectural University, for their help.

\section{REFERENCES}

[1] T. Harima, Y. Suzuki and T. Sone, "Influence of time difference and/or level difference for synthetic sound image," Mem. Tohoku Inst. Technol. Ser. I Sci. Eng., 22, 135-144 (2002).
[2] T. Harima, S. Takane, Y. Suzuki and T. Sone, "Localization of virtual sound image generated by two sources located on the median plane," J. Acoust. Soc. Jpn. (E), 18, 205-208 (1997).

[3] R. Y. Litovsky, H. S. Colburn, W. A. Yost and S. J. Guzman, "The precedence effect," J. Acoust. Soc. Am., 106, Pt. 1, 16331654 (1999).

[4] R. M. Dizon and H. S. Colburn, "The influence of spectral, temporal, and interaural stimulus variations on the precedence effect," J. Acoust. Soc. Am., 119, 2947-2964 (2006).

[5] T. Yanagisawa and T. Nimura, "On experimental results of correlation between physical and psychological quantities in room acoustics - On experimental results in artifical sound field obtained in anechoic room-, J. Acoust. Soc. Jpn. (J), 24, 111-125 (1968) (in Japanese).

[6] C. Spence, Translation: Y. Igarashi and N. Kitagawa, "Audiovisual multisensory integration,” J. Acoust. Soc. Jpn. (J), 63, 83-92 (2007) (in Japanese).

[7] M. B. Gardner, "Proximity image effect in sound localization," J. Acoust. Soc. Am., 43, 163-169 (1964).

[8] M. B. Gardner, "Image fusion broadening and displacement in sound localization," J. Acoust. Soc. Am., 46, 339-349 (1969).

[9] S. Komiyama, "Interaction between vision and auditory in spatial perception,” J. Acoust. Soc. Jpn. (J), 52, 46-50 (1996) (in Japanese).

[10] S. Iwamiya, "Multimodal communication by music and motion picture," J. Acoust. Soc. Jpn. (J), 52, 40-45 (1996) (in Japanese).

[11] S. Iwamiya, "The effects of the large display reproduction of video on the impression of sound and picture when listening to music via audio-visual media," J. Acoust. Soc. Jpn. (J), 51, 123-129 (1995) (in Japanese).

[12] M. Sakurama and K. Ohgushi, "Conveyance of the player's ideas for performances of percussion - Interaction between auditory and visual processing_," J. Acoust. Soc. Jpn. (J), 48, 613-622 (1994) (in Japanese).

[13] H. Haas, "Über den Einfluß eines Einfachechos auf die Hörsamkeit von Sprache [On the influence of a single echo on the intelligibility of speech]," Acustica, 1, 29-58 (1951).

[14] H. Wallach, E. B. Newman and M. R. Rosenzweig, "The precedence effect in sound localization," Am. J. Psychol., 57, 315-336 (1949).

[15] W. Burgtorf, "Untersuchungen zur Wahrnehmbarkeit verzögerter Schallsignale [Investigations of the perceptibility of delayed sound signals]," Acustica, 11, 97-111 (1961).

[16] H. P. Seraphim, "Über dic Wahrnehmbarkeit mehrerer Rückwürfe von Sprachschall [On the perceptibility of multiple reflections of speech sounds]," Acustica, 13, 75-85 (1961).

[17] M. Morimoto, M. Ishii and Z. Maekawa, "Influence of a visual stimulus on echo-threshold," J. Acoust. Soc. Jpn. (J), 46, 229235 (1990) (in Japanese).

[18] K. Maruyama and T. Sasaki, "Intersensory effects across vision and audition," J. Acoust. Soc. Jpn. (J), 52, 34-39 (1996) (in Japanese).

[19] Y. Tahara, H. Sato and S. Nishitani, "A study on auditory integration characteristics based on critical time delay for distinct perception of echo," J. Acoust. Soc. Jpn. (J), 61, 14-23 (2005) (in Japanese).

[20] Y. Ogura, T. Sone and Y. Suzuki, "On the errors in estimates when the method of maximum likelihood was applied to the result of psycho-acoustical experiment obtained by the constant method," J. Acoust. Soc. Jpn. (J), 45, 441-445 (1989) (in Japanese). 